\title{
A FORMAÇÃO DO CONTRATO OBRIGATÓRIO - SUAS RAÍZES ROMANAS
}

\author{
José Carlos Moreira Alves \\ Professor Titular do Departamento de Direito Civil da \\ Faculdade de Direito da Universidade de São Paulo
}

\begin{abstract}
Resumo:
O autor aborda os princípios da formação dos contratos no Direito moderno, partindo das fontes Romanas quanto às normas de constituição dos contratos nas atuais codificações. Em seguida, a evolução do conceito de contrato, desde os seus primórdios, passando pelo Direito Romano até o Direito moderno.
\end{abstract}

Abstract:

The author approaches the beginnings of the formation of the contracts in the modern Right. leaving of the Roman sources of relationship to the norms of the constitution of contracts in the current codes. Soon after, the evolution of the contract concept, from your origins, going by the Roman Right until the modern Right.

Unitermos: formação e conceito de contratos.

Sumário:

1. Os princípios da formação dos contratos obrigatórios no Direito moderno.

2. A parcimônia da indicação das fontes romanas quanto às normas de formação dos contratos nas codificações modernas.

3. A evolução do conceito de contrato e dos princípios sobre sua formação do Direito Romano ao Direito moderno.

4. A formulação dos princípios da formação dos contratos obrigatórios com base nas fontes romanas. 
1. Os princípios da formação dos contratos obrigatórios no Direito moderno.

Nos Códigos Civis, a partir do Código da Prússia, de 1794 - e, portanto, dos fins do século XVIII - até os mais recentes como o do Paraguai, promulgado em dezembro de 1985 -, encontram-se, nos mais deles, princípios sobre a formação dos contratos obrigatórios. Naqueles que não tratam especificamente dessa matéria - e é o que ocorre com o Código Civil francês e com os que o seguiram de perto, a doutrina e a jurisprudência dos países em que eles vigoram se encarregam de, por construção, suprir essa lacuna, valendo-se, inclusive, da generalização de preceitos relativos a contratos típicos, especialmente os que se classificam como consensuais.

Esses princípios, que estão estreitamente ligados ao conceito de contrato obrigatório como acordo de vontades de que decorre o nascimento, a modificação ou a extinção de obrigações, dizem respeito, basicamente, à eficácia da punctação ou tratativas (acordos preparatórios), aos diversos problemas concernentes à oferta e à aceitação, às questões referentes à inserção automática de cláusulas impostas pela ordem jurídica e à contratação com cláusulas-padrões ou com módulos ou formulários.

Nos Códigos mais modernos - e isso já se dá com o Código Civil italiano de 1942 -, essa disciplina é mais rica do que se verifica com relação às codificações mais antigas, não-só em virtude do aprofundamento do exame dessas questões, mas também pela freqüência da utilização de contratos de adesão e de contratos-tipos, a demandar regulamentação legislativa para maior segurança jurídica.

Resultado dessa tendência é o recente Projeto Unidroit sobre princípios para os contratos comerciais internacionais, que, na verdade, não é um projeto de tratado internacional, mas de regras que as partes contratantes, ressalvadas as normas cogentes dos países a que pertencem, concordam em observar, e regras essas que, decorrentes da sedimentação de estudos de Direito comparado nesse terreno, visam a dar tratamento o mais possível uniforme a contratos cujas partes são de paises diversos, caminhando-se, assim, no sentido da futura uniformização das legislações nacionais.

O enunciado das matérias articuladas nesse projeto propicia uma visão global do que há de mais recente e abrangente no tocante a princípios 
relativos à formação dos contratos obrigatórios:

artigo 2.1 (definição de oferta);

artigo 2.2 (retirada da oferta);

artigo 2.3 (revogação da oferta);

artigo 2.4 (recusa da oferta);

artigo 2.5 (modo de aceitação);

artigo 2.6 (momento em que produz efeito a aceitação);

artigo 2.7 (aceitação dentro de um prazo fixado);

artigo 2.8 (aceitação tardia; atraso na transmissão);

artigo 2.10 (aceitação com modificações);

artigo 2.11 (confirmação por escrito);

artigo 2.12 (aperfeiçoamento do contrato condicionado a um acordo);

artigo 2.13 (contrato com cláusulas deliberadamente deixadas em aberto);

artigo 2.14 (negociações de má-fé) ;

artigo 2.15 (dever de sigilo);

artigo 2.16 (cláusulas de incorporação);

- artigo 2.17 (cláusulas de modificação escrita) ;

- artigo 2.18 (contratação com cláusulas-padrões);

artigo 2.19 (estipulações inesperadas);

- artigo 2.20 (conflito entre cláusulas-padrões e outras que não o sejam); e

artigo 2.21 (intercâmbio de formulários).

2. A parcimônia da indicação das fontes romanas quanto às normas de formação dos contratos nas codificações modernas.

Quando se procura estudar a origem dos diferentes princípios modernos sobre a formação dos contratos obrigatórios, verifica-se, mesmo com relação a códigos com larga vinculação à tradição jurídica-romana e tomo como exemplo os Códigos Civis argentino, brasileiro e italiano: o primeiro é de meados do século XIX (1869); o segundo, do começo deste século (1916); e o terceiro, de pouco antes de sua metade (1942) -, que, nas poucas obras que se dedicaram a 
identificar as bases romanísticas de seus textos sobre essa matéria, quase nada se encontra.

Salvatore di Marzo, alguns anos após a promulgação do Código Civil italiano, escreveu ampla obra Le Basi Romanistiche del Codice Civile em que procurou estabelecer as concordâncias e, por vezes, as discordâncias entre a disciplina feita pelos artigos dessa codificação e os textos jurídicos romanos. Nas premissas desse livro, anotou ele:

"Uma das características do novo Código Civil é o decidido retorno, em muitos pontos, à tradição romana, eliminadas as superestruturas que não respondem às exigências do nosso pensamento jurídico e da prática atual, considerada na sua realidade. O conhecido movimento, que fora da Itália acumulava acusações sobre acusações contra o Direito Romano, não podia, de fato, instigar os nossos melhores juristas, que tinham a missão de preparar a nova legislação, a prezar maiormente o rico patrimônio de experiencias herdado da antiga Roma e a ressuscitar noções e normas às quais o legislador de 65 havia preferido o produto de uma reelaboração não sempre necessária, às vezes inoportuna e não-raro equivocada. E é especialmente de notar o freqüente retorno às concepções do Direito clássico, que o Direito justinianeu havia rechaçado, julgando que não tivessem suficientemente em conta as relações da vidu" 1

Não-obstante, porém, tenha o Código Civil italiano disciplinado pormenorizadamente os diferentes aspectos da formação dos contratos nos arts. 1.326 a 1.342, as anotações de Di Marzo sobre as bases romanísticas desses dispositivos são extremamente parcimoniosas, limitando-se a três deles: ao 1.326 (que trata do momento da conclusão do contrato pela aceitação, bem como do princípio de que a aceitação não-conforme a proposta equivale à nova proposta), ao 1.337 (que diz respeito às tratativas e à responsabilidade pré-contratual) e ao 1.338

1. Le Basi Romanistiche del Codice Civile, Torino, 1950, p. 4. 
(relativo à responsabilidade da parte que, conhecendo ou devendo conhecer uma causa de invalidade do contrato, não deu conhecimento disso à outra).

Quanto ao art. 1.326, adstringe-se Di Marzo, após salientar que, no Direito Romano clássico, o acordo das partes contratantes só tinha especial relevo nos contratos que geravam obrigações recíprocas, como a venda, a locação, a sociedade, o mandato - e cita as Institutas de Gaio, III, 137 ("in his contractibus alter alteri obligabitur de eo, quod alterum alteri ex bono et aequo praestare oportet") - a assinalar que os contratos consensuais se celebram também entre ausentes (Gaio, III, 126: "veluti per epistulam aut per internuntium, cum alioquin verborum obligatio inter absentes fieri non possit"), o que igualmente é atestado por outras fontes (D. XVII, 1, pr.-1: "Obligatio mandati consensu contrahentium consistit. Ideo per nuntium quoque vel per epistulam mandatum suscipi potest"; D. XVIII, 1, 1, 2: "Est autem emptio iuris gentium, et ideo consensu peragitur et inter absentes contrahi potest et per nuntium et per litteras"; e D. XVII, 2, 4, pr.: "Societatem coire et re et verbis et per nuntium posse nos dubium non est"). E, ainda sobre esse dispositivo, conclui: "Mas, da eficácia jurídica da proposta as fontes romanas não se ocupam" 2

No concernente ao art. 1.337, restringe-se o romanista italiano a dizer, sem citar fontes: "o Direito Romano operava com a noção do dolo". 3

E, no tocante ao art. 1.338, é igualmente sucinto, sem referir fontes: "Esta era responsabilidade in contrahendo pelo comportamento doloso da parte que conhecia a causa de invalidade do contrato: referia-se aos negócios que davam margem a um julgamento de boa-fé" 4

Também extremamente parcimoniosas no tocante à identificação das fontes romanas dos textos do Código Civil brasileiro relativos à formação dos contratos, são as obras que, no Brasil, têm procurado fazê-lo. E note-se - que é exata essa observação feita por Gaetano Sciascia, que lecionou alguns anos na Faculdade de Direito da Universidade de São Paulo:

$$
\begin{aligned}
& \text { "É bem sabido que o Código Civil brasileiro assumiu } \\
& e \text { desenvolveu nas suas linhas gerais a obra da }
\end{aligned}
$$

\footnotetext{
2. Ob. cit., p. 245.

3. Ob. cit., p. 245

4. Ob. cit., p. 245 .
} 
pandectística do século XIX. Quase a cada artigo da lei podem buscar-se os correspondentes textos romanos, os quais apresentam as relativas fatispécias na mais viva realidade e na infinita variedade dos acontecimentos humanos. Sobre este ponto de vista o sistema das obrigações é sem dúvida a parte mais interessante do Direito Romano". 5

No Código Civil brasileiro, os preceitos referentes à formação dos contratos se encontram no capítulo das Disposições Gerais deles, arts. 1.079 a 1.088.

Nos comentários a esse Código, escritos pelo autor de seu Anteprojeto

Clóvis Bevilaqua, em cada artigo há a indicação, sob a rubrica direito comparado, da correspondência do texto com o de outras codificações modernas e os do Direito Romano. Com relação, todavia, aos dispositivos acima referidos, a única anotação concernente ao Direito Romano diz respeito ao art. 1.080, que reza: "A proposta de contrato obriga o proponente, se o contrário não resultar dos termos dela, da natureza do negócio, ou das circunstâncias do caso" E a anotação é esta: "Em sentido diferente. Inst. 3, 23, pr." 6

Já Vieira Ferreira autor de O Código Civil Anotado, onde, com relação a cada artigo, indica, sob a rubrica direito antigo, as fontes do Direito brasileiro e português anteriores ao Código, bem como as romanas - vai um pouco além. Com relação ao art. 1.079 ("A manifestação da vontade, nos contratos, pode ser tácita, quando a lei não exigir que seja expressa"), cita as seguintes passagens do Digesto:

"Gaius libro singulari de formula hypotecaria. In re hypothecae nomine obligata ad rem non pertinet, quibus fit verbis, sicuti est et in his obligationibus, quae consensu contrahuntur; et ideo et sine scriptura si convenit, ut hypothecae sit, et probari poterit, res obligata erit de qua conveniunt. Fiunt enim de his scripturae, ut quod actum est per eas facilius probari

5. Direito Romano e Direito Civil Brasileiro, São Paulo, 1947, p. 205.

6. Código Civil dos Estados Unidos do Brasil Comentado, $4^{\mathrm{a}}$ ed., Rio de Janeiro, 1934, v. IV, p. 247. 
possit: et sine his autem valet quod actum est, si habeat probationem, sicut et miptiae sunt, licet testatio sine scriptis habita est" (D. XXII, 4, 4);

"Callistratus libro secundo quaestionum: Si res gesta sine litterarum quoque consignatione veritate factum suum praebeat, non ideo minus valebit, quod instrumentum nullum de ea intercessit" (D. XXII, 4, 5);

"Paulus libro tertio ad edictum: Non figura literarum, sed oratione, quam exprimunt litterae, obligamur, quatemus placuit non minus valere, quod scriptura, quam quod vocibus lingua figuratis significaretur" (D. XLIV. 7, 38);

"Modestinus libro secundo regularum. .... 9. Etiam nudus consensus sufficit obligationi, quamvis verbis hoc exprimi possit. 10. Sed et mutu solo pleraque consistunt" (D. XLIV. 7. 52, 9 e 10); e

"Ulpianus libro octavo ad adictum: Delegare scriptura vel nutu, ubi fari non potest, debitorem summ quis potest" (D. XLVI, 2, 17). ${ }^{7}$

E, com referência ao art. 1.080 ("A proposta de contrato obriga o proponente, se o contrário não resultar dos termos dela, da natureza do negócio, ou das circunstâncias do caso"), diverge de Clóvis Bevilaqua, aludindo a fragmentos do Digesto que, a seu ver, teriam alguma correspondência com esse dispositivo do Código Civil brasileiro:

"Iavolenus libro duodecimo epistularum: In omnibus rebus, quae dominium transferunt, concurrat oportet affectus ex utraque parte contrahentium: nam sive ea venditio sive donatio sive conductio sive quaelibet alia causa contrahendi fuit, nisi animus utriusque consentit, perduci ad effectum id quod inchoatur non potest" (D. XLIV, 7, 55); e 
"Ulpianus libro quarto disputatinum: Pactum est duorum consensus atque conventio, pollicitatio vero offerentis solius promissum. Et ideo illud es constitutum, $u t$, si ob honorem pollicitatio fuerit facta, quasi debitum exigatur, sed et coeptum opus, licet non ob honorem promissum, perficere promissor eo cogetur, el est constitutum" (D. L, 12, 3, pr.). ${ }^{8}$

Não é diferente o panorama com relação ao Código Civil argentino, que disciplina a formação dos contratos nos arts. 1.144 a 1.156. O autor de seu projeto Velez Sarsfield - deixou numerosas notas aos diversos dispositivos que integram esse Código, indicando nelas as fontes em que se baseou. Nessas notas, com relação aos mencionados artigos, não há a indicação de qualquer texto juridico romano correspondente. Há apenas, quanto aos arts. 1.150 a 1.154 (que tratam da formação do contrato entre ausentes), esta observação: "Quando se forma o contrato por correspondência é matéria que dividiu os jurisconsultos franceses. As Leis Romanas não apresentam nenhuma resolução sobre esta delicada questão" 9 Observa, porém, Augustín Díaz Bialet ${ }^{10}$ que, quanto ao art. 1.145 do Código Civil argentino (que declara que o consentimento, no contrato, pode ser expresso ou tácito), Sarsfield invoca como fonte o obra do romanista Maynz, em seu $\S 284$, ${ }^{\prime \prime}$ onde este, aludindo à indiferença de forma pela qual as partes dão o seu consentimento, cita, na nota 9, como fontes romanas dessa firmação, D. XXII, 4, 4; D. XXII, 4, 5; D. XLIV, 7, 38; D. XLIV. 7. 52, 9 e 10; e D. XLVI, 2, 17, que são as mesmas fontes que Vieira Ferreira viria como já vimos a citar como correspondentes ao art. 1.079 do Código Civil brasileiro, retirando-as certamente da obra de Maynz. Por outro lado, o mesmo Augustín Díaz Bialet, ${ }^{12}$ no tocante aos arts. 1.150 a 1.154 do Código Civil argentino, contesta a afirmação de Sarsfield sobre o silêncio das fontes romanas a propósito, entendendo que a diretriz para a solução dos

8. Ob. cit., p. 473

9. Codigo Civil de la Republica Argentina com las notas de Velez Sarsfield, edição aos cuidados de Luis Alberto Éstivill, Buenos Aires, 1969, p. 273.

10. El Derecho Romano y la Obra de lelez Sarsfield, Cordoba, 1952, p. 130.

11. Essa passagem se encontra na última edição da obra de Maynz (Cours de Droit Romain, tomo II, Bruxelles-Paris, 1891) na nota 9 ao $\$ 200$, p. 151.

12. Ob. eit., v. III, p. 130. 
casos práticos sobre essa questão é dada por três textos do Digesto - II, 14, 2 ("Paulus libro tertio ad edictum: Labeo ait convenire posse vel re vel per epistulam ver per nuntium inter absentes quoque posse. Sed etiam tacite consensu convenire intellegitur: et ideo si debitori meo reddiderim cautionem, videtur inter nos convenisse ne peterem, profuturamque ei conventionis exceptionem placuit"); XVIII, 1, 1, 2 ("Est autem emptio iuris gentium, et ideo consensu peragitur et inter absentes contrahi potest et per nuntium et per litteras"); e XLIV, 7, 2, 2 ("Unde inter absentes quoque talia negotia contrahuntur, veluti per epistulam vel per nuntium") - aclarados por estas palavras de Cícero a Ático (na carta 41, citada por Troplong, De la Vente, n. 22); "Romae enim videor esse quum tuas litteras lego, et modo hoc modo illuc audire"; e arremata Bialet:

"O texto de Paulus, D. XLV, 1, 83, pr. dispõe que: $O$ negócio se contrata entre o que estipula e o que promete"

"Para nós isso significa que o diálogo jurídico, que fará ou não o contrato, ocorre ao escrever um a oferta e ao responder, aceitando ou não, o outro. E essa é precisamente a doutrina seguida pelo Codificador' 13

Como se vê, é bastante parcimoniosa a indicação das fontes romanas das normas do Direito moderno no tocante à formação dos contratos obrigatórios. Essas normas não derivaram de princípios jurídicos romanos? Como se formaram elas?

3. A evolução do conceito de contrato e dos princípios sobre sua formação - do Direito Romano ao Direito moderno.

Durante toda a evolução do Direito Romano, só se enquadram entre os contratos os acordos de vontade que se destinam a criar relações juridicas obrigacionais. Em Roma, nem todo acordo de vontades lícito gera obrigações: contrato (contractus) e pacto (pactum, conventio) eram acordos de vontades, mas aquele produzia obrigações, ao passo que este, em regra, não. Portanto, o Direito Romano somente conheceu os contratos obrigatórios e não-acolheu pelo menos até 
Justiniano o princípio, existente no Direito moderno, de que todo acordo de vontades lícito, ainda que não se amolde a um dos tipos de contrato reconhecidos pela ordem jurídica, pode produzir relações jurídicas obrigacionais.

Do Direito clássico ao justinianeu, o sistema contratual romano sofre alterações profundas, observando-se, nessa evolução, uma constante: o alargamento gradativo do círculo de acordos de vontades a que a ordem jurídica concede a eficácia de geral obrigações.

No Direito clássico, os juristas, ao invés de conceberem o contrato como uma categoria geral e abstrata, conheciam apenas alguns tipos de contrato (contractus), em que segundo a concepção romana - não é o acordo de vontades (elemento subjetivo pressuposto no contrato) que faz surgir a obrigação, mas, sim, um elemento objetivo (observância de formalidades, ou entrega da coisa: forma ou datio rei). O simples acordo de vontades (pactum, conventio) não-gera obrigação, sendo tutelado, não por uma actio, mas, indiretamente, por uma exceptio: daí a máxima nuda pactio obligationem non parit, sed parit exceptionem. Portanto, contrato e acordo de vontades (pactum, conventio) não se confundem, no Direito clássico.

Mas, ainda no período clássico, e, depois, no pós-clássico, esse esquema rígido (contrato $=$ acordo de vontade + elemento objetivo que faz surgir a obrigação) sofre atenuações. Já no tempo de Gaio, ao lado das obligationes re, verbis e litteris (isto é, obrigações nascidas de contratos que seguiam esse esquema), há quatro contratos consensuais, em que a obrigação nasce apenas do consensus (consentimento; acordo de vontades): obligationes consensu. Por outro lado, graças à jurisprudência, ao pretor e ao imperador, certos pactos (os pactos vestidos, na pitoresca linguagem dos autores medievais: pactos adjectos, pretorianos e legítimos) passam a gerar obrigações, embora os juristas romanos não os enquadrem entre os contractus. Possivelmente no Direito pós-clássico, a tipicidade contratual sofre abalo com a admissão da categoria dos contratos inominados, isto é, contratos atípicos, que formam uma categoria abstrata, e que têm, em comum, a unidade de ação que os tutela e o fato gerador da obrigação: a execução, por um dos contratantes, de sua prestação faz nascer, para o outro, a obrigação de efetuar a contraprestação.

No Direito justinianeu, o panorama está inteiramente modificado: os juristas bizantinos, ao invés de considerarem, como os clássicos, que a obrigação nasce do elemento objetivo (forma ou datio rei), e não do acordo de vontades, entendem que é deste que resulta a obrigação: o acordo de vontades, de mero 
pressuposto de fato dos contratos, passa a ser seu elemento juridicamente relevante. Por isso, Teófilo, na Paraphrasis Institutionum (III, 14,2), define o contrato com palavras semelhantes às empregadas pelos juristas clássicos ao conceituarem o pacto. Mas isso significa que, no tempo de Justiniano, vigorava o princípio existente no Direito moderno - de que todo acordo de vontades lícito gera obrigação? Riccobono $^{14}$ e Sanfilippo ${ }^{15}$ respondem afïrmativamente, por entenderem que uma constituição do Imperador Leão, de 472 d. C. (C. VIII, 37, 10), acabou, totalmente, com o formalismo da stipulatio, resultando daí que todo acordo de vontade, sem quaisquer formalidades, tinha eficácia como sendo stipulatio, não havendo, assim, mais lugar para os pactos nus. A maioria dos romanistas, porém, responde negativamente, salientando que, ainda no Direito justinianeu, persiste a categoria dos pactos nus e, sob certo aspecto, a tipicidade contratual, pois os juristas bizantinos continuam a entender que cada contrato tem uma figura própria e autônoma, embora admitam que os contratos possam introduzir, nos casos concretos, mudanças, supressões ou acréscimos nos tipos contratuais, desde que sejam compatíveis com a natureza do contrato típico (natura contractus), em outras palavras, no Direito justinianeu, ao invés da rede rígida de tipos contratuais que se encontra no período clássico, há uma rede mais elástica.

Por outro lado e, a propósito, sintetizo as informações de Schlossmann ${ }^{16}$ e de Marsson ${ }^{17}$ sobre a evolução dos princípios relativos à oferta e à aceitação -, no Direito Romano, a maioria dos contratos era entre presentes. O caráter formal do Direito Romano mais antigo exigia a unidade de tempo, de lugar e de ação, concentração essa que é observada na mancipatio, no nexum, na iure cessio, na stipulatio, no testamentum. Ademais, para celebrar contratos em lugares onde o paterfamilias não-podia estar presente, podia ele se valer, como de uma longa manus, de seus escravos e de seus filii familias, certo como era que o que estes adquiriam revertia para o patrimônio daquele. Modalidade das mais utilizadas de contrato era a stipulatio que exigia a presença das partes contratantes. No âmbito do ius gentium é que vão surgir os contratos que se podem celebrar entre ausentes. Sempre entre ausentes era o contrato litteris.

14. Corso di Diritto Romano - Stipulationes Contractus Pacta, Milano, 1935. pp. 31 c ss

15. Alla Ricerca de "Nuda Pacla". in Atti.del Congresso Internazionale di Diritlo Romano e di Storia del Diritto, v. III, Verona, 1948, pp. 337 e ss.

16. Der Vertrag, Leipzig, 1876, pp. 140 e ss.

17. Die Natur der Vertragsofferte, Grefsivald. 1879, pp. 9 e ss. 
Por causa de os contratos serem comumente celebrados entre presentes e para isso concorria, também, a circunstância de, em Roma, o sistema de correios não ser aberto aos particulares , os juristas romanos encaravam o contrato com uma unidade orgânica e não, como os modernos, como um todo composto de duas metades: a oferta e a aceitação. No Direito Romano, não há designação técnica para esses dois institutos. A oferta, como observa Marsson, ${ }^{18}$ se exprime com expressões como sic dicere (D. XVIII, 1, 35, 1), sic emptum rogare (D. XVIII, 1, 41); e com relação à stipulatio, os textos usam das expressões actus stipulandi, actus promittendi, ou ainda stipulari e interrogare em contraposição a promittere, spondere, respondere. É a partir dos glosadores que começa a surgir, quanto aos contratos obrigatórios, uma terminologia geral. Baseada no D. L, 12, 3, pr. (Pactum est duorum consensus atque conventio, pollicitatio vero offerentis sollus promissum), acentua a glosa: el sic non est ibi consensus nisi unius partis; semelhantemente, com relação ao D. II, 14, 1, 2 (et est pactio duorum pluriumve in idem placitum consensus), observa ela: per hoc a pollicitatione differt, cum pollicitatio sit solius offerentis promissio. Donde decorre que, para os glosadores, tanto na pollicilatio quanto no pactum há uma promessa, que, no pactum, é acrescida de uma característica: a ocorrência da acceptatio promissionis. Por isso o que não se encontra nas fontes romanas, glosadores, pós-glosadores e os seguidores do mos italicus conceituam o pactum como acceptatio promissionis. A palavra oferta só vai surgir no século XVII, provavelmente entre os comerciantes, para os quais oferta era o oferecimento de coisa ou de prestação. Posteriormente, entre os juristas, se encontra o emprego da palavra oblatio com o significado de oferta, como se vê na obra de Rudloff (De acceptatione et eius iure, Altdorffi, 1676): "unius partis oblatio et alterius acceptatio haec duo consensus contrahentium nomine efferantur" $\mathrm{O}$ aparecimento do conceito de oferta corresponde ao surgimento da óptica jusnaturalista, que vê no contrato uma transmissão de direito, e na promessa a oferta de um direito. Identifica-se a oferta com a promessa, e já no século XIX, em seu terceiro quartel, Koeppen ${ }^{19}$ define a oferta como a promessa de uma prestação que se faz com vistas a concluir um contrato obrigatório; e Siege ${ }^{20}$ acentua que a oferta é a

18. Ob. cil., p. 13

19. Der obligalorische Vertrag unter Abw'esenclen. in lahrbücher für die Dogmatik des heutigen römischen und deutaschen Privalrechls, v. XI, p. 354

20. Das Verpreschen als lerpflichtungsgrund in heutigen Recht, Berlin, 1873, p. 53. 
promessa dada para o caso de sua aceitação. A oferta não é mais o oferecimento de uma prestação, mas o elemento que propicia ao oblato fazer nascer um contrato.

Como se vê, não se encontra no Direito Romano, sequer no tempo de Justiniano, uma teoria geral do contrato, ainda que restrita ao contrato obrigatório. $\mathrm{O}$ próprio princípio fundamental para o sistema das regras de formação dos contratos no Direito moderno os contratos, em geral, se formam com o simples acordo de vontades, sendo excepcional que além do consentimento se exija um elemento formal (contratos solenes) ou uma prestação (contratos reais) é o resultado de uma longa evolução que permite à Escola do Direito Natural iniciar, no século XVIII, o movimento de teorização do contrato, movimento esse que alcança sua culminância, na centúria seguinte, com os pandectistas alemães. A essas duas correntes do pensamento jurídico é que se devem a formulação e a sistematização dos princípios de formação dos contratos.

Mas, também nesse terreno, a doutrina se formou à luz das fontes romanas. Vale aqui a observação de Biondo Biondi de que, embora os autores, para explicarem historicamente a transformação que se deu com a identificação do contractus com a conventio, invoquem, geralmente, os direitos germânico e canônico, "em realidade as fontes romanas dcrvam bases suficientes para construir a doutrina geral do contrato, que se concebe nos tempos modernos, tornando explícito o que era implícito nas fontes, eliminando o dualismo entre contractus e pactum e, conseqüentemente, colocando na sombra o princípio de que do pacto nu não pode nascer ação, ou superando-o por via de expedientes" 21

Em se tratando das regras da formação dos contratos, não há fontes diretas romanas de que pudessem se valer os juristas a partir da Idade Média. Valeram-se eles, no entanto, para a construção dessas regras, da generalização de princípios relativos a institutos jurídicos que tivessem algum traço em comum com os contratos em seu conceito moderno - e fizeram isso principalmente com o pactum, a stipulatio, os contractus consensu, a traditio , ou da extração de argumento dessas fontes indiretas, ou da sua aplicação analógica; e, partindo da fixação de princípios gerais, com o destaque, inclusive, de textos romanos com normas conflitantes, os desenvolveram racionalmente, encontrando outras soluções, e abrindo, assim, opções ao legislador do movimento de codificações iniciado nos fins do século XVIII. Daí a razão por que, nessas codificações, muitas de suas normas nesse terreno resultam do 
que se tornou explícito com relação ao que era implícito nas fontes romanas, ou de soluções racionais que se opuseram às formuladas com alguma base nas fontes romanas, explicando-se, assim, a parcimônia da indicação de textos romanos nas obras como as referidas no item 2 deste trabalho que se atém apenas aos que sejam mais evidentemente vinculados aos artigos da codificação.

No próximo item, dar-se-á uma amostra de como essa construção de princípios se fez principalmente no século XIX e início do século XX, e especialmente por obra de autores alemães.

4. A formulação dos princípios da formação dos contratos obrigatórios com base nas fontes romanas.

É a partir do século passado que a doutrina se ocupou mais intensamente do problema dos princípios da formação dos contratos obrigatórios. Nas obras que trataram dessa questão, especialmente nas dos autores germânicos - e isso se explica pela vigência na Alemanha até o final da centúria do Direito comum há a preocupação de se estabelecerem esses princípios à luz do que se podia extrair, a respeito, dos textos romanos sobre os contractus, os pacta e outros institutos jurídicos em que se pudessem entrever princípios que, generalizados, se amoldassem ao problema do consentimento nos contratos.

Observa Regelsberger $^{22}$ que três são os elementos que condicionam a conclusão de um contrato obrigatório: que as partes concordem sobre todos os pontos essenciais do negócio; que estejam conscientes desse acordo; e que tenham declarado sua vontade com intenção vinculante e na forma exigida.

Para afirmar que o contrato é perfeito quando a vontade dos contratantes se manifesta sobre todos os pontos essenciais na forma devida e com a intenção de obrigar-se, Arndts ${ }^{2.3}$ invoca duas fontes romanas: uma relativa aos pactos - D. II, 14, 1, 1 a 3 (" I. Pactum autem a pactione dicitur (inde etiam pacis nomen appellatum est) 2. Et est pactio duorum pluriumve in idem placitum consensus. 3. Conventionis verbum generale est ad omnia pertinens, de quibus negotii contrahendi transigendique causa consentiunt qui inter se agunt: nam sicuti convenire dicuntur qui ex diversis locis in unum locum colliguntur et veniunt, ita et

22. Civiliechliche Erorterungen. erstes Helfi. Weinar. 1868, p. 134.

23. Lehrbuch der Pandekten, 14" ed. \$231, Stullgarl, 1889, p. 456. 
qui ex diversis animi motibus in unum consentiunt, id est in unam sententiam decurrunt. Adeo autem conventionis nomen generale est, ut eleganter dicat Pedius nullum esse contractum, nullam obligationem, sive re sive verbis fiat: nam et stipulatio quae verbis fit, nisi habeat consensum, nulla est") - e outra referente à compra e venda D. XVIII, 1, 9, do qual a parte que interessa é a que se encontra no princípio desse fragmento: "Ulpianus libro vicensimo octavo ad Sabinum: In venditionibus et emptionibus consensum debere intercere palam est: ceterum sive in ipsa emptione dissentiant sive in pretio sive in quo alio, emptio imperfecta est" Baron $^{24}$ (p. 353), porém, com base no segundo desses textos, sustenta que o contrato não se aperfeiçoa se se fecha acordo quanto aos essentialia negotii, mas não quanto aos naturalia e aos accidentalia negotii.

Com relação aos contratos entre presentes, adverte Arndts $^{25}$ que a declaração de aceitar uma promessa pode preceder à promessa, na forma de pergunta, como ocorria com a stipulatio; que entre as duas declarações (a oferta e a aceitação) pode decorrer algum tempo, como resulta de dois fragmentos do Digesto sobre stipulatio: D. XLV, 1, 1, 1 ("Qui praesens interrogavit, si antequam sibi responderetur discessit, inutilem efficit stipulationem; sin vero praesens interrogavit, mox discessit et reverso responsum est obligat: intervallum enim medium non vitiavit obligationem") e D. XLV. 2, 12, pr.: "Venuleius libro secundo stipulationum: Si ex duobus qui promissuri sint hodie alter, alter postera die responderit, Proculus non esse duos reos ac ne obligatum quidem intellegi eum qui postera die responderat, cum actor ad alia negotia discesserit vel promissor, licet peractis illis rebus responderit" embora reconheça que esses textos não dão regra genérica para se saber por quanto tempo deve considerar-se como perdurando a oferta; e que a declaração de um dos contratantes permanece ineficaz enquanto o outro não a tenha compreendido, como decorre de um texto das Institutas de Justiniano 1. 3, 15, sobre a stipulatio: "Utrum autem Latina an Graeca vel qua alia lingua stipulatio concipiatur, nihil interest, scilicet si uterque stipulantium intellectum huius linguae habeat" - e de três fragmentos do Digesto, um sobre a stipulatio D. XLV. 1, 1, pr. ("Ulpianus libro quadragesimo octavo ad Sabinum: Stipulatio non potest confici nisi utroque loquente: et ideo neque mutus neque surdus neque infans stipulationem contrahere possunt: nec absens quidem, quoniam

24. Pandekten, $6^{\mathrm{a}}$ ed., $\$ 212$, p. 353.

25. Ob. cit., p. 457 
exaudire invicem debent. Si quis igitur ex his vult stipulari, per servum praesentem stipuletur, et adquiret ei ex stipulatu actionem, item si quis obligari velit, iubeat et erit quod iussu obligatus" e os outros dois sobre as obrigações e as ações - D. XLIV, 7, 1, 15: "Sed et de surdo idem dicitur, quia, etiamsi loqui possit, sive promittit, verba stipulantis exaudire debet, sive stipuletur, debet exaudire verba promittentis. Unde apparet non de eo nos loqui, qui tardius exaudit, sed qui omnino non exaudit", e D. XLIV 7, 48: "Paulus libro sexto decimo ad Plautium: In quibuscumque negotiis sermone opus non est sufficiente consensu, iis etiam surdus intervenire potest, quia potest intellegere et consentire, velut in locationibus conductionibus, emptionibus et ceteris" Embora entre a oferta e a aceitação possa mediar algum tempo, salienta Scheurl ${ }^{26}$ que, em regra, a aceitação, nos contratos entre presentes, deve ser feita imediatamente após a oferta, como se extrai de três fragmentos do Digesto: D. XLV, 1, 1, 1 (já transcrito), D. XLV. 2, 6, 3 ("Duo rei sine dubio ita constitui possunt, ut et temporis ratio habeatur, intra quod uterque respondeat: modicum tamen intervallum temporis, item modicus actus, qui modo contrarius obligationi non sit, nihil impedit, quo minus duo rei sunt fideiussur quoque interrogatus inter duorum reorum responsa si responderit, potest videri non impedire obligationem reorum, quia nec longum spatium interponitur nec is actus, qui contrarius sit obligationi") e D. XLV, 2, 12, pr. (também já-transcrito anteriormente), todos sobre a stipulatio. E, ainda a esse propósito, observa Grisostomi $^{27}$ que, em geral, se as conversações terminam sem que seja dada a resposta, ou passam a tratar definitivamente de outro assunto, a oferta, salvo pacto em contrário, caduca, como se vê dos três textos que acabamos de citar (D. XLV, 1, 1, 1; D, XLV. 2, 6, 3 e D. XLV, 2, 12) e de mais um: D. XLV. 1, 137, pr. ("Venuleius libro primo stipulationum: Continuus actus stipulantis et promittentis esse debet (ut tamen aliquod momentum naturae intervenire possit) et comminus responderi stipulanti oportet: ceterum si post interrogationem aliud acceperit, nihil proderit, quamvis eadem die spopondisset").

Para demonstrar que os romanos admitiam contratos consensuais entre ausentes, vale-se Wendt ${ }^{28}$ de um fragmento do Digesto, atribuído a Gaio; D. XLIV, 2,1 e 2 ("..., Ideo autem istis modis consensu decimus obligationem contrahi, quia

26. Beitrüge zur Bearbeitung des Römischen Rechts, Erlangen, 1853, pp. 301-303.

27. Ob. cit., p. 116.

28. Lehrbuch der Pandekten, Tena, 1888, pp. 490-491. 
neque scripturae ulla proprietas desideratur, sed sufficit eos, qui negotia gerunt, consentire. 2. Unde inter absentes quoque talia negotia contrahuntur, veluti per epistulam vel per nutium"). Outros dois textos são invocados por $\mathrm{Arndts}^{29}$ ao acentuar que o contrato entre ausentes se celebra por meio de mensageiro ou de carta - D. Il, 14, 2, pr. ("Paulus, libro tertio ad edictum: Labeo ait convenire posse vel re vel per epistulam ver per nuntium inter absentes quoque posse, sed etiam tacite consensu convenire inttellegitur:..."); e D. XVII, 1, 1, pr.-§ 2 ("Paulus libro trigensimo secundo ad edictum: Obligatio mandati consensu contrahentium consistit. 1. Ideo por nuntium quoque vel per epistulam mandatum suscipi potest. 2. Item sive "rogo" sive "volo" sive "mando" sive alio quocumque verbo scripserit, mandati actio est"), o primeiro relativo aos pactos e o segundo ao contrato de mandato. Vering, ${ }^{30}$ porém, observa que as fontes romanas indicam os meios pelos quais se celebra o contrato entre ausentes, mas não dizem quando esse contrato se perfaz. A esse respeito, salienta Ferrini ${ }^{31}$ que modernamente há principalmente três teorias que procuram fixar o momento em que se conclui o contrato entre ausentes: $a$ da declaração (basta que o aceitante envie sua declaração de vontade conforme a proposta recebida por isso, alguns a denominam teoria da expedição), a da recepção (é preciso que a declaração de vontade do aceitante chegue ao proponente) e a da cognição (a declaração de vontade do aceitante deve chegar ao proponente e ser por ele conhecida), sendo que, em seu entender, a teoria da cognição parece ter sido a única admitida pelos romanos. Argumenta Ferrini ${ }^{32}$ com o conceito de pactum ("duorum in idem placitum et consensus" D. II, 14, 1, 2), advertindo que consensus não significa apenas vontade comum, mas também vontade reciprocamente conhecida, bem como com dois textos no sentido de que o surdo não pode celebrar stipulatio (D. XLIV. 7, 1, 15 e D. XLV, 1, 1, pr., cujos teores já transcrevemos anteriormente), o que significa que não basta que a resposta (que pode ser ouvida por outros) chegue a ele, mas é preciso que ele tenha percepção dela. Por outro lado, rebate ele o argumento que alguns retiram, em favor da teoria da declaração, da aplicação analógica do D. XL, 2, 4, pr. ("Iulianus libro quadragensimo secundo

29. Ob. cit., $\$ 231$, p. 458 .

30. Geschichte und Pandekten des römischen und heutigen gemeinen Privatrechts, $5^{\mathrm{a}}$ ed., nota 1 , Mainz, 1887, §190, p. 522.

31. Obbligazione, in Enciclopedia Giuridica Italiana, v. XII - Parte I, n. 440, Milano, 1923, p. 661.

32. Ob. cit, n. 440 , p. 661 . 
digestorum: Si pater filio permiserit servum manumittere et interim decesserit intestato, deinde filius ignorans patrem suum mortuum libertatem imposuerit, libertas servo favore libertatis contingit, cum non appareat mutata esse domini voluntas. Sin autem ignorante filio vetuisset pater per nuntium et antequam filius certior fieret, servum manumisisset, liber non fit. Nam ut filio manumittente servus ad libertatem perveniat, durare oportet patris voluntatem: nam si mutata fuerit, non erit verum volente patre filium manumisisse"), observando que a razão de ser dessa solução decorre do fato de que para o escravo conseguir a liberdade pela manumissão feita pelo filho é preciso que persista a vontade do pai (durare oportet patris voluntatem) no momento da manumissão, o que não-ocorre com o contrato em que se exige o concurso de duas vontades, não-bastando, portanto, a declaração da aceitação, mas que as vontades dos contratantes se encontrem, o que só ocorre quando proponente e aceitante têm consciência da existência de ambas as vontades. Pela teoria da cognição entre os romanos, já se manifestara anteriormente Regelsberger, ${ }^{33}$ citando, além do D. XLIV 7, 1, 15 e do D. XLV. 1, 1, o texto do D. XLIV, 7, 48 (todos eles já-transcritos), e argumentando, ainda, com a circunstância de que a stipulatio pressupõe que o contratante saiba a língua do outro. Também Baron $^{34}$ diz que em favor da teoria da cognição parece haver o caso do surdo, acrescentando o texto que se encontra nos Tituli ex Corpore Ulpiani, XX, 13: "Mutus surdus furiosus itemque prodigus, cui lege bonis interdictum est, testamentum facere non possunt: mutus quoniam verba nuncupationis loqui non potest: surdus, quoniam verba familiae emptoris exaudire non potest:...").

No concernente à oferta e à aceitação, há várias questões que os autores examinam à luz de fontes jurídicas romanas.

É muito controvertido se, no Direito Romano, se admitiam propostas de contrato in incertas personas. Giovanni Baviera ${ }^{35}$ bem demonstra que tanto os textos trazidos ao debate pelos autores que o negam (assim, Ihering, Kindervater, Pernice, Lucci, Messina) - e são estes: D. I, 7, 18; D. XLV. 3, 10; D. XLV, 3, 21; D, XLV. 3, 11; e D. XLV, 3, 9) quanto os invocados pelos que o defendem (Sohm, Ferrini, Köppen, Krückmann) e são estes: D. XLI, 1, 9, 7, relativo ao iactus missilium; I. II, 20, 25-27; D, XV. 4, 1, pr.; e I. IV, 7, 8) não oferecem elementos

33. Pandekten, v. I, § 150, Leipzig, 1893, p. 553.

34. Ob. cit., $\$ 212$, p. 352 .

35. L'offerta al Pubblico, in Enciclopedia Giuridica Italiana, separata, Milano, 1907, pp. 7 e ss. 
conclusivos para decidir essa questão, mas propiciaram elementos para a formulação das posições modernas a esse respeito.

Windscheid ${ }^{36}$ adverte que a oferta pode ser revogada enquanto a outra parte não declarou aceitá-la, e deduz isso dos textos relativos a que o surdo não pode celebrar a stipulatio (D. XLIV. 7, 1, 15 e D. XLV, 1, 1, pr.). A mesma dedução faz para chegar ao princípio de que a aceitação pode revogar-se enquanto ela não chega ao proponente. Sustenta, porém - coerente com sua tese de que os romanos teriam acolhido a teoria da declaração (baseia-se, para isso, no D. XL, 2, 4, pr., e cita ainda - D. XXIV. 2, 7: "Papinianus libro primo de adulteriis: Si paenituit eum, qui libellum tradendum divortii dedit, isque per ignorantiam mutatae voluntatis oblatus est, durare matrimonium dicendum, nisi paenitentia cognita is qui accepit ipse voluit matrimonium dissolvere: tunc enim per eum qui accepit solvitur matrimonium") , que, num e noutro casos, a eficácia da declaração de revogação não depende de que esta chegue à outra parte, baseando-se, para isso, no D. XL, 2, 4, pr. e no D. XXIV, 2, 7, e rebatendo o entendimento da maioria dos autores em sentido contrário, por entender que as fontes por eles invocadas (D. XVII, 2, 17, 1: "Si absenti renuntiata societas sit, quod is scierit, quod is adquisivit qui renuntiavit in commune redigi, detrimentum autem solius eius esse qui renuntiaverit: sed quod absens adquisit, ad solum eum pertinere, detrimentum ab eo factum commune esse"; D. XVII, 1, 15: "Paulus libro secondo ad Sabinum: Si mandassem tibi, ut fundum emeres, postea sctipsissem, ne emeres, $t u$, antequam scias me vetuisse, emisses, mandati tibi obligatus ero, ne damno adficiatur is qui suscipit mandatum"; D. XLVI, 3, 12, 2: "Sed et si quis mandaverit, ut Titio solvam, deinde vetuerit eum accipere: si ignorans prohibitum eum accipere solvam, liberabor, sed si sciero, non liberabor"; e D. XIV. 6, 12: "Paulus libro trigensimo ad edictum: Si tantum sciente patre creditum sit filio, dicendum est cessare senatus consultum. Sed si iusserit pater filio credi, deinde ignorante creditore mutaverit voluntatem, locus senatus consulto non erit, quoniam initium contractus spectandum est") ou só contêm a máxima de que aquele a quem se determinou agir não pode ser prejudicado com a retirada dessa declaração ocorrida sem seu conhecimento, ou - como sucede com o D. XVII, 2, 17, 1 - não podem ser aplicadas por analogia. Nessa linha, entende, ainda, Windscheid ${ }^{37}$ 186.

36. Diritto delle Pandette, v. Il, ristampa stereotipa, trad. Fadda-Bensa, §307, Torino, 1930, p.

37. Ob. cit., § 307, pp. 186-187. 
que o que revoga é obrigado, em favor da outra parte, que, ignorando a revogação, confiou em que estivesse formado o contrato, a indenizá-la pelo que Ihering denominou interesse negativo do contrato; e se baseia para isso no princípio geral de que todo contratante deve responder pelas conseqüências danosas ocasionadas à outra parte que confiou na aquisição do direito de crédito com base no contrato, princípio geral esse que extrai de fragmentos do Digesto relativos à promessa de algo impossível: D. XI, 7, 8, 1 ("Si locus religiosus pro puro venisse dicetur, praetor in factum actionem in eum dai ei ad quem res pertinet: quae actio et in heredem competit, cum quasi ex empto actionem contineat"); D. XVIII, 1, 62, 1 ("Qui nesciens loca sacra vel religiosa vel publica pro privatis comparavit, licet emptio non teneat, ex empto tamen adversus venditorem experietur, ut consequatur quod interfuit eius, ne deciperetur"); e D. XVIII, 4, 8 e 9 ("8. lavolenus libro secundo ex Plautio: Quod si nulia hereditas ad venditorem pertinuit, quantum emptori praestare debeat, ita distingui oportebit, ut, si est quidem aliqua hereditas, sed ad venditorem non pertinet, ipsa aestimetur, si nulla est, de qua actum videatur, pretium dumtaxat et si quid in eam rem impensum est emptor a venditore consequatur. 9. Paulus libro trigensimo tertio ad edictum: Et si quid emptoris interest"). A grande maioria dos autores, todavia, é contra essa generalização, e Waechter $^{38}$ acentua que as fontes nada dizem a respeito. O princípio de que a aceitação condicionada ou limitada se traduz em nova proposta é retirado por Windsheid" ${ }^{39}$ do D. XLV, 1, 1, 3: "Si quis simpliciter interrogatus responderit: "si illud factum erit, dabo", non obligati eum constat: aut si ita interrogatus: "intra kalendas quintas?", responderit: "dabo idibus" Aeque non obligatur: non enim sic respondit, ut interrogatus est. Et versa vice si interrogatur fuerit sub condicione, responderit pure, dicendum erit eum non obligari. Cum adicit aliquid vel detrahit obligationi, semper probandum est vitiatam esse obligationem, nisi stipulatori diversitas responsionis ilico placuerit: tunc enim alia stipulatio contracta esse videtur" Grisostomi ${ }^{40}$ acrescenta que "se entre a proposta e a aceitação há diferença somente quantitativa, ter-se-á uma válida aceitação até a concorrência da quantia compreendida assim na proposta como na aceitação", observando que, a esse respeito, nesse sentido há duas fontes (D. XLV, 1, 1, 4: "Si stipulanti mihi

38. Pandekten, v. II, Leipzig, 1881, p. 359.

39. Ob. cit., $§ 407$, p. 192.

40. Le Promesse di Contrattare, Frascati, 1903, p. 135, nota 1. 
"decem" tu "viginti" respondeas, non esse contractam obligationem, nisi in decem constat. Ex contrario quoque si me "viginti" interrogante tu "decem" respondeas, obligatio nisi in decem non erit contracta: licet enim oportet congruere summam, attamen manifestissimum est viginti et decem inesse"; e D. XLV, 1, 83, 3: "Diversa causa est summarum, velut "decem aut viginti dari spondes?" hic enim etsi decem spoponderis, recte responsum est, quia semper in summis id, quod minus est, sponderi videtur"); em sentido contrário, porém, também há duas fontes (Gaio, Inst. III, 102: "Adhuc inutilis est stipulatio, si quis ad id quod interrogatus erit, non responderit, veluti si sestertia $X$ a te dari stipuletur, et tu sestertia V promittas, ..."; e I. III, 19, 5: "Praeterea inutilis est stipulatio, si quis ea, quae interrogatus erit, non responderit, veluti si decem aureos a te dari stipuletur, tu quinque promittas, ..."). De outra parte, é controvertido o princípio segundo o qual não se aperfeiçoa o contrato se, quando da aceitação, já se encontra morto o proponente. Windscheid ${ }^{41}$ se manifesta afirmativamente, baseando-se, principalmente, no D. XXXIX. 5, 2, 6 ("Sed si quis donaturus mihi pecuniam dederit alicui, ut ad me perferret, et ante mortuus erit quam ad me perferat, non fieri pecuniam dominii mei constar") e no D. XLI, 2, 33 ("Pomponius libro trigensimo secundo ad Sabinum: Fundi venditor etiamsi mandaverit alicui, ut emptorem in vacuam possessionem induceret, priusquam id fieret, non recte emptor per se in possessionem veniet. Item si amicus venditoris mortuo eo, priusquam id sciret, aut non prohibentibus heredibus id fecerit, recte possessio tradita erit. Sed si id fecerit, cum sciret dominum mortuum aut cum sciret heredes id facere nolle, contra erit"). No mesmo sentido, Dernburg, ${ }^{42}$ citando o D. XXXIX, 5, 2, 6, embora reconheça que a questão é controvertida. Igualmente, na Itália, Ferrini. ${ }^{43}$ Contra, entre outros, Regelsberger. ${ }^{44} \AA$ A morte salienta Windscheid, ${ }^{45}$ e nesse sentido também se manifesta Ferrini ${ }^{46}$ se equipara, para o mesmo efeito, a incapacidade de fato superveniente.

Outra questão é a de saber se, quando as partes contratantes convencionam certa forma (escritura) para o contrato, se ela é condição

41. Ob. cit., $\$ 307$, p. 191

42. Pandette, v. II (Diritto delle Obbligazioni), trad., Cicala, § I1, p. 40 e nota 16.

43. Ob. cit., $\$ 444$, p. 666 .

44. Ob. cit., $\$ 150$, p. 551 , nota 18

45. Ob. cit., §307, p. 191

46. Ob. cit., $\$ 444$, p. 666 
indispensável para que este se forme. Arndts ${ }^{47}$ responde pela afirmativa, observando, ainda, que, se as partes tiverem convencionado certa forma depois de concluído o contrato, se presumirá, na dúvida, terem querido que essa forma sirva apenas para a prova do contrato e não para a sua validade. Cita a propósito o D. XXII, 4, 4: "Gaius libro singulari de formula hypothecaria: In re hypothecae nomine obligata ad rem non pertinet, quibus fit verbis, sicuti est et in his obligationibus, quae consensu contrahuntur: et ideo et sine scriptura si convenit, ut hipothecae sit, et probari poterit, res obligata erit de qua conveniunt. Fiunt enim de his scripturae, ut quod actum est per eas facilius probari possit: et sine his autem valet quod actum est, si habeat probationem, sicut et nuptiae sunt, licet testatio sine scriptis habita est" Dernburg $^{48}$ observa que Justianiano, no pacto da documentação, quer reconhecer uma condição do contrato, e cita, a respeito, I. III, 23, pr. ("In his autem, quae scriptura conficiuntur, non aliter perfectam esse emptionem et venditionem constituimus, nisi et instrumenta emptionis fuerint conscripta vel manu propria contrahentium, vel ab alio quidem scripta, a contrahente autem subscripta et, si per tabellionem fiunt, nisi et completiones acceperint et fuerint partibus absolutas. Donec enim aliquid ex his deest, et poenitentiae locus est et potest emptor vel venditor sine poena recedere ab emptione") e a constituição de que foi tirado esse princípio (C. IV, 21, 17).

Note-se, por fim, que os romanos não conheceram a figura das condições gerais dos contratos, as quais são cláusulas-padrões formuladas por uma das partes sem ser negociadas com a outra. Podem elas constar de módulos ou formulários pelos quais o proponente fixa, total ou parcialmente, o conteúdo do contrato. Elas podem ser impostas, ou-não, ao aderente, sendo que, quando impostas, há, propriamente, o que se denomina contrato de adesão.

Brasília, junho de 1998. 